\title{
Rhazya Stricta Assisted Green Synthesis of Multifunctional Carbon Coated Copper Oxide Nanosheets for Photocatalysis of Dyes and Antibacterial Candidate Against Solanaceous Pathogens
}

\section{Hamida Bibi}

The University of Agriculture Peshawar, Pakistan

Dr. Mudassar lqbal ( $\square$ mudassariqbal@aup.edu.pk)

The University of Agriculture Peshawar, Pakistan

\section{Hassan Wahab}

Pakistan Institute of Nuclear Science and Technology

Mehmet Öztürk

Muğla University

Fei Ke

Anhui Agricultural University

\section{Zafar lqbal}

The University of Agriculture Peshawar, Pakistan

\section{Muhammad Ishfaq Khan}

The University of Agriculture Peshawar, Pakistan

\section{Suliman Mohammed Alghanem}

University of Tabuk

\section{Research Article}

Keywords: Green synthesis, Copper oxide nanosheets, Rhazya stricta, Ralstonia solanacearum, Clavibacter michiganensis, Photodegradation, Methylene blue

Posted Date: March 17th, 2021

DOl: https://doi.org/10.21203/rs.3.rs-289812/v1

License: (1) This work is licensed under a Creative Commons Attribution 4.0 International License. Read Full License 


\section{Abstract}

The studies of metal oxides in environmental remediation of chemical and biological pollutants are gaining huge importance. Herein, we report the facile synthesis of multi-functional copper oxide nanosheets (CuO NS) using an aqueous extract of Rhazya stricta. The phytochemical investigation of $R$. stricta indicated the presence of saponins, tannins, and reducing sugars responsible for the reduction and stabilization of CuO NS. The formation of CuO NS was confirmed by x-ray diffraction and UV-visible spectrophotometer with specific Surface Plasmon Resonance at $294 \mathrm{~nm}$. Further characterization of the CuO NS was done by FE-SEM, FTIR, and XRD. The obtained CuO NS were poly-dispersed with an average size of $20 \mathrm{~nm}$. Interestingly these particles were aligned together in the form of 3D cubical sheets layered above each other via self-assembly. The as-synthesized CuO NS shows enhanced antibacterial potential ( $17.63 \mathrm{~mm}$, mean inhibition zone) as compared to the known antibiotics ( $11.51 \mathrm{~mm}$, mean inhibition zone) against the wilt causing bacteria of Solanaceous crop, including Ralstonia solanacearum and Clavibacter michiganensis. Furthermore, the appreciable photocatalytic potential of CuO NS has been observed, causing $83 \%$ degradation of methylene blue (MB) upon solar irradiation. The synthesis methodology is devoid of any toxic waste and/or by-products and could be used to produce eco-friendly $\mathrm{CuO}$ nanomaterial for industrial uses.

\section{Introduction}

Metal oxide nanostructures have drawn considerable interest due to their enhanced photocatalytic properties, low cost and wide range of biological and industrial applications ${ }^{12}$. Besides having excellent antimicrobial properties, metal oxide nanoparticles could be used for drug delivery, having increased resistance against multidrug resistance (MDR) pathogens. Metal nanostructures such as silver ( $\mathrm{Ag}$ ), gold ( $\mathrm{Au}$ ), and Iron ( $\mathrm{Fe})$ have been widely studied for their bioactivity and applications in various consumer products ${ }^{345}$. These can be synthesized using different methods, including chemical ${ }^{6}$, electrochemical ${ }^{7}$, sol-gel ${ }^{8}$ and condensation ${ }^{9}$, etc. but with certain limitations such as the generation of hazardous waste, use of toxic chemicals and solvents, the difficulty in optimizing the extent of scaling up synthetic processes, and utilization of high energy ${ }^{10}$. The recent development in nanotechnology combined with green chemistry, led to the development of environmentally friendly, non-toxic, and cost effective procedures for the fabrication of nanomaterials ${ }^{11}$. Due to the large surface to volume ratio, the nanomaterials are highly reactive and results in extremely beneficial properties, including mechanical, biochemical, biotechnology, optics, catalysis, and medicines ${ }^{12}$.

Recently copper oxide nanostructures have gained attention due to their low cost in comparison to the existing metal nanoparticles such as $\mathrm{Ag}$ and $\mathrm{Au}$. They are also considered almost ten times cheaper than their other counterparts. Copper oxide nanostructures are believed to have high sensitivity against both Gram-negative \& Gram-positive microorganisms. They have a high potential as an external microbial agent and in the form of biocidal film over medical devices ${ }^{13}$. However, very limited studies are available for their use in agriculture for the control of pathogens.

Wilting of Solanaceous crops caused by bacteria, including Ralstonia solanacearum and Clavibacter michiganensis is of major concern for the growers ${ }^{14}$. Both of these bacteria spread rapidly on their outbreak and cause severe damage by clogging the vascular system through extracellular polysaccharides ${ }^{1516}$. These 
pathogenic bacteria are generally controlled by using commercially available antibiotics that are expensive and pose threats to the environment. Furthermore, rapid industrialization and excess use of dyes are posing a severe threat to the water quality and biotic ecology. These organic pollutants are highly mutagenic and carcinogenic to human life. Dyes are poorly degradable pollutant and their complex chemical structure make them difficult to remove from water ${ }^{17}$. Therefore, it is of utmost importance to have eco-friendly products for the control of these pathogens and for the removal of both biological and chemical pollutants.

To the best of our knowledge, there has not been any report on the single-step one-pot synthesis procedure carbon-coated CuO-NS using an aqueous extract of $R$ stricta. Herein, we report a one-pot, environmentally friendly method for the fabrication of multi-functional CuO NS for photocatalytic degradation of methylene blue (MB) and their possible use as a bio-control agent against wilt causing bacterial pathogens of Solanaceous crops to enhance quality and agricultural productivity.

\section{Materials And Methods}

\section{Collection of plant material}

The experiment and collection of plant material is done in accordance with the relevant national and international guidelines. ${ }^{18}$ Arial parts of Rhazya stricta (Wild), were collected with permission from local forest officers in the month of April 2020 from district Karak, Khyber Pakhtunkhwa, Pakistan, located at $33^{\circ} 7^{\prime} 12 \mathrm{~N}$ $71^{\circ} 5^{\prime} 41 \mathrm{E}$ (Figure 1). The plant samples were stored in a paper bag and transferred to the laboratory within 48 hours and identified by Dr. Muhammad Ishfaq Khan. A specimen of the sample was deposited in a special herbarium for weeds and medicinal plants (voucher No. MIK-5/20-397), Department of weed science, The University of Agriculture Peshawar. The collected samples were rinsed with distilled water and air-dried under shade for 14 days. The dried samples were chopped into small pieces using a sterile scissor, and the sample was boiled at $60^{\circ} \mathrm{C}$ distilled water for $20 \mathrm{~min}$ ( $10 \%$ weight to volume ratio) on the heating mantle. The solution was cooled to room temperature and vacuum filtered to obtain the aqueous extract concentrate (brown color) and stored at $4^{\circ} \mathrm{C}$ for further use.

\section{Qualitative analysis of Phytochemicals}

The phytochemical contents of Rhazya stricta, including alkaloid, phenols, flavonoids, terpenoid, saponins, steroids, tannins, and anthraquinones, were assessed using standard procedures 1920 .

\section{Biosynthesis of CuO NS}

For the synthesis of CuO NS, $60 \mathrm{~mL}$ of freshly prepared aqueous extract of Rhazya stricta was added to $80 \mathrm{~mL}$ of $0.5 \mathrm{M}$ aqueous copper sulfate pentahydrate $\left(\mathrm{CuSO}_{4} \cdot 5 \mathrm{H}_{2} \mathrm{O}\right)$ solution at room temperature. A prominent change in color from blue to green was observed as soon as both solutions come in contact, which indicates the reduction of ionic copper. The obtained green mixture upon heating at $80^{\circ} \mathrm{C}$ for 12 hours turned to the brown mixture. The reaction mixture was then allowed to cool at room temperature, and the brown suspended particles were separated through centrifugation (10000 RPM for $10 \mathrm{~min}$ ). The precipitates were thoroughly washed with distilled water and absolute ethanol to remove unreacted reagents and biomolecules. The obtained solid material was dried under $\mathrm{N}_{2}$ flow and stored at $4{ }^{\circ} \mathrm{C}$ for further characterization. 


\section{Characterization Copper Oxide Nanosheets}

\section{UV-visible spectral analysis}

The bio-reduction of $\mathrm{Cu}^{2+}$ ion solution through an aqueous extract of Rhazya stricta was monitored using Optima Sp3000+ (Japan) split beam UV-vis spectrometer for its maximum absorption v/s wavelength range against the aqueous extract of Rhazya stricta as a blank. Upon completion, the reaction mixture was centrifuged at 10,000 rpm for 10 minutes to eliminate any uncoordinated bio-molecules. The obtained solid material was re-suspended in double-distilled de-ionized water and scanned from 200-1100 nm wavelength.

\section{Fourier transform infrared spectroscopy (FT-IR) analysis}

The Fourier Transform Infrared spectra were recorded under identical conditions in the range $400-4000 \mathrm{~cm}^{-1}$ region using FTIR Spectrometer (SHIMADZHU; Japan).

\section{X-ray diffraction analysis}

The phase identity, crystalline structure, and crystallite size were determined from the XRD data using Cu-ka radiation source. The CuO NS powder was coated on a glass substrate and submitted for their crystal structure analysis. The results were recorded as a graph with $2 \theta$ vs. intensity at the $x$-axis and y-axis, respectively.

\section{Field Emission Scanning electron microscopy (FE-SEM)}

The surface morphology and size distribution of as-synthesized CuO NS were characterized using TESCAN MAIA3 Field Emission Scanning Electron Microscopy (FE-SEM). A drop of an aqueous solution of Cu NS obtained after purification via repeated centrifugation was placed on a Silicon (Si) substrate and let to dry. The samples were then characterized at an accelerated voltage of $5.0 \mathrm{kV}$.

\section{Antibacterial Assays}

Synthesized CuO NS were tested for inhibition against the wilt-causing bacterial pathogens of Solanaceous crops, including Ralstonia solanacearum and Clavibacter michiganensis. The antibacterial assay was carried out by the disc diffusion method ${ }^{21}$. Both bacterial strains were developed using nutrient broth at $38^{\circ} \mathrm{C}$ for 24 hours and then streaked over Potato Dextrose Agar's surface using sterile cotton swabs. The sterile paper disk ( $5 \mathrm{~mm}$ ) was adsorbed with $10 \mu \mathrm{L}$ of the reaction mixture, and the disc was placed on the surface of the plate.

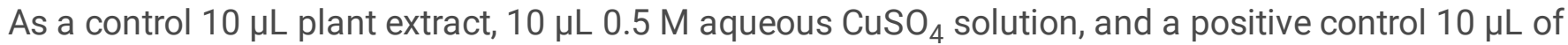
streptomycin (0.5 M in distilled water) were separately adsorbed on sterile paper discs ( $5 \mathrm{~mm}$ ). It was then placed on a prepared lawn of bacterial cultures on PDA to assess their effect on pathogens. The plates were incubated at $38^{\circ} \mathrm{C}$ for 24 hours, and bacterial growth inhibition was observed as clear halos (zones) around the discs.

\section{Photocatalytic property}

The photocatalytic potential of biogenic CuO NS was carried out at the end of May under sunlight irradiation. To $100 \mathrm{~mL}\left(10 \mu \mathrm{g} \mathrm{mL}^{-1}\right)$ aqueous methylene blue solution in a transparent flask, $10 \mathrm{mg}$ of synthesized CuO NS were added and allowed to stir for 2 hours and 20 minutes under direct sunlight. A control experiment (in the 
absence of CuO NS) was also maintained simultaneously. After every 20 min of reaction duration, $5 \mathrm{~mL}$ sample aliquot was collected and centrifuged (10000 rpm) for 6 minutes to remove suspended CuO NS. The supernatant was collected and examined by a UV-Vis spectrophotometer at $\lambda_{\max } 664 \mathrm{~nm}$ for the estimation of available unreacted MB. The following formula was used to determine the percent photo-degradation efficiency (PD\%) of MB.

$P D \%=\frac{\mathrm{C}_{0}-\mathrm{C}_{t}}{\mathrm{C}_{0}} \mathrm{X} 100$

Where PD\% denote percent photodegradation, $\mathrm{C}_{0}$ and $\mathrm{C}_{\mathrm{t}}$ represents the absorbance of $\mathrm{MB}$ at time 0 min and $\mathrm{t}$ $\min$

\section{Statistical analysis}

The data was obtained in triplicates. The antibacterial activity is presented as a mean zone of inhibition ( $\mathrm{mm}$ ) $\pm S$.E, the different letters in columns are statistically significant at $\mathrm{P}<0.05$

\section{Results And Discussion}

The detection of phytochemical in aqueous extract of Rhazya stricta revealed the presence of various groups of bioactive natural products (Table 1). These natural products, especially polyphenols, are believed to be responsible for the reduction of metal ions and the formation of metallic nanoparticles ${ }^{22}$.

Table 1 Phytochemical analysis of Rhazya stricta, + shows the presence and - shows the absence of molecules

\begin{tabular}{|c|c|c|c|c|c|c|c|}
\hline & Saponins & Alkaloids & Tannins & Flavonoids & Polyphenols & Anthraquinones & Steroids \\
\hline $\begin{array}{l}\text { Rhazya } \\
\text { stricta } \\
\text { aqueous } \\
\text { extract }\end{array}$ & + & + & + & + & + & - & - \\
\hline
\end{tabular}

\section{Biosynthesis of CuO NS}

The synthetic procedure for CuO NS using an aqueous extract of Rhazya stricta is very simple, environmentally friendly, and cost-effective. Here the $\mathrm{CuSO}_{4}$ dissolved in water dissociates into $\mathrm{Cu}^{2+}$ and $\mathrm{SO}_{4}{ }^{2-}$ ions. The $\mathrm{Cu}^{2+}$ is then reduced to $\mathrm{CuO}$ by the action of biomolecules (predominantly polyphenols) present in the aqueous extract of Rhazya stricta. The generated metallic copper nuclei then start growing into nanosheets. These NS are then stabilized by several biomolecules from Rhazya stricta distributed around the growing Cu NS. This copper NS then starts precipitating due to water insolubility. The unreacted biomolecules sticking the surface of nanoparticles were removed during washing with distilled water and ethanol, resulting in pure dark brown CuO nanosheets. 


\section{UV-Vis spectroscopy analysis}

The addition of aqueous extract of Rhazya stricta to the $\mathrm{CuSO}_{4}$ solution caused a change in the color from blue to green. Upon heating at $80^{\circ} \mathrm{C}$ turned brown, indicated the biosynthesis of CuO NS (Figure 2-A). This change in the color is due to the excitation of surface Plasmon vibration of CuO NS, which generated a highintensity peak appearing at $294 \mathrm{~nm}$ and a minor peak at 314 could be from the different size/shape of CuO NS (Figure 2-B Inset) ${ }^{23}$. We opined that this is also attributed to the $n \rightarrow \pi^{\star}$ transition of $\mathrm{C}=0$ bonds ${ }^{24}$. The peak appearing at $226 \mathrm{~nm}, 244 \mathrm{~nm}$ and $258 \mathrm{~nm}$ (Fig 2-B inset) in the low-frequency region are the characteristic peaks of graphene nanosheets corresponding to the $\pi$ conjugation network or $\pi \rightarrow \pi^{*}$ transition ${ }^{25}$. The presence of low-frequency peaks (Figure 2-B-inset) confirms that the biomolecules present in the aqueous extract of Rhazya stricta might have played a role in the reduction and stabilization of CuO NS. Amorphous carbon has a less sharp peak and a long band tail in comparison to graphitic carbon ${ }^{26}$. The peak positions of onion-like nano carbon depended on the shell structure. For example, the spherical, polyhedral, and ribbon-like onion structures had peaks at 233,241 , and $249 \mathrm{~nm}$, respectively ${ }^{27}$. Tan and co-workers ${ }^{28}$ have attributed the peak at $220 \mathrm{~nm}$ to a disordered and defective carbon. The high-frequency peaks might be attributed to the existence of nanoribbon like carbon sheets surrounding the CuO NS.

The bandgap of CuO NS was determined using the Tauc plot method ${ }^{29}$, by plotting (ahv) ${ }^{2}$ versus $h v$, as shown in Figure 2(C), where $a$ is the absorption coefficient and $h v$ is the energy of incident light, $h$ is Planck's constant $\left(6.626 \times 10^{-34} \mathrm{Js}\right)$ and $v$ is the frequency of light. Based on tauc's plot, the bandgap was calculated as $3.84 \mathrm{eV}$. A similar energy band gap $(3.85 \mathrm{eV})$ was reported by Dhineshbabu and co-workers while studying the structural and optical properties of cupric oxide nanoparticles synthesized via sonochemical method ${ }^{30}$. More recently, a slightly higher bandgap of $4.01 \mathrm{eV}$ of $\mathrm{CuO}$ NS has been reported using melanin as a stabilizer agent 31.

\section{X-Ray Diffraction Analysis}

Figure 3 shows the X-ray diffraction (XRD) pattern of the carbon-coated CuO NS. Overall the spectrum shows an amorphous nature of the CuO NS. However, there also appears some small diffraction peak at $2 \theta=23.8^{\circ}$, $2 \theta=31.90^{\circ}, 2 \theta=38.52^{\circ}$ and a weak shoulder at $2 \theta=41.22^{\circ}$, which confirms the growth of crystals and the formation of some crystalline planes. The peaks appearing at $2 \theta=23.8^{\circ}$ and $2 \theta=41.22^{\circ}$ are believed to be due to the emergence of (002) and (102) respectively for graphene oxide and the peaks appearing at $2 \theta=$ $31.90^{\circ}, 2 \theta=38.52^{\circ}$ are attributed to the (110) and (002) planes for $\mathrm{CuO}^{3233}$. The lattice spacing determined from the (002) $\nabla$ plane is of the order of $0.37 \mathrm{~nm}$, while for crystalline graphite, the lattice spacing remains about $0.34 \mathrm{~nm}$. The slightly higher $\mathrm{d}$ spacing value suggests the presence of some oxygen functional groups between the carbon layers. Besides this, the broadened peak corresponding to the (002)『 plane is believed to be due to the disordered carbon structure indicating the formation of graphene sheets as observed by Ashish and Sundara ${ }^{34}$, which might be due to the self-assembly of carbon atoms.

\section{Fourier transform infrared spectroscopy (FT-IR) analysis}


Various bio-molecules having different functional groups were responsible for reducing $\mathrm{CuSO}_{4}$ and then stabilizing CuO NS derived from bioactive molecules. Various functional groups were found to be attached to nanoparticles' surface during synthesis. FTIR is one of the most important techniques used to identify functional groups attached to nanomaterials' surface. Figure 4 shows a sharp band appearing at $630 \mathrm{~cm}^{-1}$, the characteristics band of pure monoclinic CuO reported earlier ${ }^{35}$. The peak appearing at $1040 \mathrm{~cm}^{-1}$ is attributed to the $\mathrm{C}-\mathrm{H}$ stretching vibrations. A sharp absorption band at $1600 \mathrm{~cm}^{-1}$ is believed to be due to the selfassembled disordered carbon sheets. The broad peak at $3297 \mathrm{~cm}^{-1}$ is believed to be due to OH groups' existence on the surface of CuO NS. A sharp absorption band at $2930 \mathrm{~cm}^{-1}$ is because of the $\mathrm{CH}$ and $\mathrm{CH}_{2}$ groups. This suggests that the hydroxyl groups might have worked as reducing and stabilizing agents for the fabrication and consequently prevented the accumulation of pure CuO NS. The appearance of bands at 1600 $\mathrm{cm}^{-1}$ and that of the $2930 \mathrm{~cm}^{-1}$ is believed to predict graphene sheets interacting with CuO NS ${ }^{36}$. Chemical linkages on the surface of CuO NS suggest that the hydroxyl and carbonyl groups might have reacted as reducing and stabilizing agents for the fabrication of $\mathrm{CuO}$ material and consequently prevented the accumulation of CuO NS.

\section{Field Emission Electron Microscopy of CuO NS}

The field emission scanning electron microscopy (FE-SEM) was used to analyze the morphology of asprepared $\mathrm{CuO}$ nanosheets, as shown in Figure 5. It can be observed that $\mathrm{CuO}$ crystallizes in the form of smaller nanoparticles, which are polydispersed and aligned together in the proper sequence. These nanoparticles, upon diffusion, lead to the formation of nanosheets. The sheet's width appears to be less than $20 \mathrm{~nm}$, which leads to highly reactive edges and corners.

\section{Antibacterial potential of CuO NS against wilt causing pathogens}

The antibacterial properties of CuO NS were evaluated against the wilt-causing bacterial pathogens of Solanaceous crops. Two bacterial strains, including Clavibactermichiganensis (gram +ve) and Ralstoniasolanacearum (gram -ve), were tested using the disk diffusion method. In the present study, the synthesized CuO NS showed significant zones of inhibitions against both bacterial strains. The Cu ions are known to disrupt various biochemical processes ${ }^{37}$. The bacterial cell wall comprises both amine and carboxyl groups ${ }^{38}$ which shows a high affinity towards the copper ions ${ }^{39}$. The CuO having a large surface to volume ratio may also bind with the nucleic acid of bacteria destroying the helical structure of DNA. The cationic Cu released from nanoparticles can attach to the negatively charged portion of the bacterial cell wall resulting in denaturation of protein and subsequently causing cell death 40 .

The zone of inhibition of CuO NS (0.25 M) against Solanaceous wilt causing bacterial strains, namely, Ralstonia solanacearum (Gram -ve) and Clavibacter michiganensis (Gram +ve), is shown in Figure 6. It is visible that Clavibacter michiganensis was more affected than Ralstonia solanacearum. The synthesized CuO NS (0.25 M)were tested in comparison to the aqueous extract of Rhazya stricta, the $\mathrm{CuSO}_{4}$ aqueous solution $(0.25 \mathrm{M})$, and known broad-spectrum antibiotic streptomycin sulfate $(0.25 \mathrm{M})$. The result is presented in Table 2 shows the biosynthesized CuO NS possessed higher antibacterial activity against both $R$. solanacearum and C. michiganensis with an inhibition zone measured as $17.30 \mathrm{~mm}$ and $17.97 \mathrm{~mm}$, respectively $(\mathrm{p}<0.05)$. 
Significantly improved antibacterial activity of the CuO NS against both tested bacterial strains was recorded compared to standard antibiotics $(p<0.05)$.

Interestingly both selected bacteria started to develop resistance after 18 hours against Streptomycin, and clear hallow around disk became turbid after 24 hours. In contrast, selected bacteria did not show any growth around CuO NS, and clear hallow remained persistent after 24 hours (Figure 6). The aqueous extract of Rhazya stricta (blank) showed no activity against both $R$. solanacearum and $C$. michiganensis. The dense growth of both bacterial isolates was seen (Figure 6, blank) around the disk containing an aqueous extract of $R$. stricta. A reason could be that the extract contains organic compounds suitable for the growth of bacterial isolates. The aqueous $\mathrm{CuSO}_{4}$ solution did not affect $R$. solanacearum, while against $C$. michiganensis, it showed a $6.43 \mathrm{~mm}$ inhibition zone. Overall, Clavibacter michiganensis was more susceptible to all experimental conditions as compare to Ralstonia solanacearum. Similarly, the mean observed effect $(17.63 \mathrm{~mm})$ of CuO NS on bacterial isolates was recorded higher than all other treatments, including positive control experiments.

Table 2 Antibacterial activity of CuO NS

\begin{tabular}{|llll|}
\hline \multirow{2}{*}{ Treatments } & \multicolumn{2}{l}{ Zone of inhibition (mean \pm S.E) } & Overall mean \\
\cline { 2 - 3 } & Ralstonia solanacearum & Clavibacter michiganensis & \\
\hline Blank & $00.00 \pm 0.00 \mathrm{a}$ & $01.18 \pm 0.00 \mathrm{a}$ & $0.593 \mathrm{a}$ \\
\hline $\mathrm{CuONS}$ & $17.30 \pm 0.40 \mathrm{~b}$ & $17.97 \pm 0.12 \mathrm{~b}$ & $17.63 \mathrm{~b}$ \\
\hline $\mathrm{CuSO}_{4(\mathrm{aqu})}$ & $00.00 \pm 0.00 \mathrm{a}$ & $6.43 \pm 0.12 \mathrm{c}$ & $3.217 \mathrm{a}$ \\
\hline Streptomycin sulfate & $08.18 \pm 0.31 \mathrm{c}$ & $14.83 \pm 0.20 \mathrm{~d}$ & $11.51 \mathrm{c}$ \\
\hline
\end{tabular}

\section{Photocatalytic potential of CuO NS}

Methylene blue (MB) is a cationic aromatic dye used in the fabric industry. It has various harmful effects on humans, livestock as well as aquatic organism. Thus, it is necessary to remove MB and other such hazardous dyes from industrial effluents. Metal oxide nanoparticles are known to possess appreciable photocatalytic behavior against various coloring pigments ${ }^{41}$. The photocatalytic behavior of synthesized CuO NS against MB was examined under direct sunlight. A clear time-dependent decrease in the absorbance band intensity of MB was observed after treatment with CuO NS. A blank degradation experiment showed merely $4.1 \%$ selfdegradation of dye after 140 minutes. The catalysts showed considerable degradation (82.7\%) of MB after 140 min of reaction. Figure 7 clearly shows an incremental increase in the degradation efficiency till 100 minutes of reaction. This could be due to the unavailability of reactive sites of CuO NS. Mali and co-workers have reported up to $90 \%$ degradation of MB using Cu nanoparticles synthesized by Celastrus paniculatus ${ }^{42}$.

The mechanism for the photocatalytic degradation of synthesized CuO NS is summarized below $\mathrm{CuONP}+\mathrm{h} v+\mathrm{MB}_{\mathrm{aq}} \rightarrow \mathrm{CO}_{2}+\mathrm{H}_{2} \mathrm{O}+$ by products

At the initial stage, the CuO NS absorbs the photons from solar irradiation and moves to a photoexcited state. In semiconducting materials, electrons are excited to the conduction band upon irradiation thereby producing 
electron-hole pairs.

$\mathrm{CuONP}+\mathrm{h} v \rightarrow \mathrm{CuOe}^{-}+\mathrm{CuO}^{+}$

The valance band holes react with the hydroxyl ion $\left(\mathrm{HO}^{-}\right)$of the water $\left(\mathrm{H}_{2} \mathrm{O}\right)$ molecule to generate hydroxyl radicals $\left({ }^{-} \mathrm{OH}^{\circ}\right)$ through oxidation. The $e^{-}$then reduces the Oxygen $\left(\mathrm{O}_{2}\right)$ to form a superoxide ion $\left({ }^{\circ} \mathrm{O}_{2}{ }^{-}\right)$.

$\mathrm{CuOh}^{+}+\mathrm{H}_{2} \mathrm{O} \rightarrow^{-} \mathrm{OH}^{\cdot}$

$\mathrm{CuOe}+\mathrm{O}_{2} \rightarrow \mathrm{O}_{2}^{-}$

These free radicals are highly reactive species causing oxidation of aromatic rings of MB dye to degrade into $\mathrm{CO}_{2}, \mathrm{H}_{2} \mathrm{O}$ and other degradation products.

$\mathrm{O}_{2}^{-}+\mathrm{HO}^{\circ}+\mathrm{MB}=$ degradation

A detailed mechanism for the photocatalytic degradation of $\mathrm{MB}$ in the presence of $\mathrm{CuO}$ NS is presented in Fig 8.

\section{Conclusion}

The successful one-pot eco-friendly synthesis of Copper NS was achieved using an aqueous extract of Rhazya stricta in 24 hours under mild conditions. Regular self-assembly of synthesized CuO NS was recorded in the form of three-dimensional cubical sheets with significant photocatalytic degradation efficiency against methylene blue. The nanosheets show a prominent bactericidal potential against wilt causing bacterial pathogens of Solanaceous plants. The Cu liberated in the field as a by-product could also be used as a micronutrient by the crops.

\section{Declarations}

\section{Acknowledgments}

The authors wish to thank the Higher Education Commission Pakistan and Turkiye burslari, Government of Turkey (vide 20PK038027) for partial support. We also thanks The University of Agriculture PeshawarPakistan, Muğla Sıtkı Koçman University, Muğla, Turkey and Pakistan Institute of Nuclear Science and Technology for providing laboratory facilities.

Competing Interests: The authors declare that they have no competing interests.

Data Availability: Data supporting the findings of this study will be available from the corresponding author upon request.

\section{References}

1. Corr, S. A. Metal oxide nanoparticles. Nanoscience 1, 180-207 (2012). 
2. Mahapatra, O., Bhagat, M., Gopalakrishnan, C. \& Arunachalam, K. D. Ultrafine dispersed CuO nanoparticles and their antibacterial activity. Journal of Experimental Nanoscience 3, 185-193 (2008).

3. Noshad, A., Hetherington, C. \& Iqbal, M. Impact of AgNPs on Seed Germination and Seedling Growth: A Focus Study on Its Antibacterial Potential against Clavibacter michiganensis subsp. michiganensis Infection in Solanum lycopersicum. J Nanomater 2019, doi:Artn 6316094 10.1155/2019/6316094 (2019).

4. Dallas, P., Sharma, V. K. \& Zboril, R. Silver polymeric nanocomposites as advanced antimicrobial agents: classification, synthetic paths, applications, and perspectives. Advances in colloid and interface science 166, 119-135 (2011).

5. Ramyadevi, J., Jeyasubramanian, K., Marikani, A., Rajakumar, G. \& Rahuman, A. A. Synthesis and antimicrobial activity of copper nanoparticles. Materials letters 71, 114-116 (2012).

6. Ethiraj, A. S. \& Kang, D. J. Synthesis and characterization of CuO nanowires by a simple wet chemical method. Nanoscale research letters 7, 70 (2012).

7. Xu, M., Wang, F., Ding, B., Song, X. \& Fang, J. Electrochemical synthesis of leaf-like CuO mesocrystals and their lithium storage properties. RSC Advances 2, 2240-2243 (2012).

8. Wang, F. et al. A highly sensitive gas sensor based on CuO nanoparticles synthetized via a sol-gel method. RSC Advances 6, 79343-79349 (2016).

9. Mageshwari, K., Sathyamoorthy, R. \& Park, J. Photocatalytic activity of hierarchical CuO microspheres synthesized by facile reflux condensation method. Powder Technology 278, 150-156 (2015).

10. Xia, T., Li, N. \& Nel, A. E. Potential health impact of nanoparticles. Annual review of public health 30, 137150 (2009).

11. Gericke, M. \& Pinches, A. Biological synthesis of metal nanoparticles. Hydrometallurgy 83, 132-140 (2006).

12. Grigore, M. E., Biscu, E. R., Holban, A. M., Gestal, M. C. \& Grumezescu, A. M. Methods of Synthesis, Properties and Biomedical Applications of CuO Nanoparticles. Pharmaceuticals 9, 75 (2016).

13. Akhavan, O. \& Ghaderi, E. Cu and CuO nanoparticles immobilized by silica thin films as antibacterial materials and photocatalysts. Surface and Coatings Technology 205, 219-223 (2010).

14. Noshad, A. et al. Antibacterial Effect of Silver Nanoparticles (AgNPs) Synthesized from Trichoderma Harzianum Against Clavibacter Michiganensis. J Nano Res-Sw 58, 10-19, doi:10.4028/www.scientific.net/JNanoR.58.10 (2019).

15. Gartemann, K.-H. et al. Clavibacter michiganensis subsp. michiganensis: first steps in the understanding of virulence of a Gram-positive phytopathogenic bacterium. Journal of biotechnology 106, 179-191 (2003).

16. Milling, A., Babujee, L. \& Allen, C. Ralstonia solanacearum extracellular polysaccharide is a specific elicitor of defense responses in wilt-resistant tomato plants. Plos one 6, e15853 (2011).

17. Ali, H. Biodegradation of synthetic dyes-a review. Water, Air, \& Soil Pollution 213, 251-273 (2010).

18. Nature, I. U. f. C. o., Commission, I. S. S., Nature, I. U. f. C. o. \& Commission, N. R. S. S. IUCN Red List categories and criteria. (IUCN, 2001).

19. Debiyi, O. \& Sofowora, F. Pytochemical screening of medical plants. Iloyidia 3, 234-246 (1978).

20. Trease, G. \& Evans, W. Phenols and phenolic glycosides. Pharmacognosy 14, 218-254 (1996). 
21. Iqbal, M. et al. MYCELIAL EXTRACT OF ACREMONIUM sp.: A POTENT TARGET SPECIFIC BIO HERBECIDE AGAINST ECHINOCHLOA CRUS-GALLI AND ASPHODELUS TENUIFOLIUS. FRESENIUS ENVIRONMENTAL BULLETIN 27, 1778-1785 (2018).

22. Devatha, C., Jagadeesh, K. \& Patil, M. Effect of Green synthesized iron nanoparticles by Azardirachta Indica in different proportions on antibacterial activity. Environmental Nanotechnology, Monitoring \& Management 9, 85-94 (2018).

23. Koffyberg, F. \& Benko, F. A photoelectrochemical determination of the position of the conduction and valence band edges of p-type CuO. Journal of Applied Physics 53, 1173-1177 (1982).

24. Li, J. \& Liu, C. y. Ag/graphene heterostructures: synthesis, characterization and optical properties. European Journal of Inorganic Chemistry 2010, 1244-1248 (2010).

25. Zhou, Y., Bao, Q., Tang, L. A. L., Zhong, Y. \& Loh, K. P. Hydrothermal dehydration for the "green" reduction of exfoliated graphene oxide to graphene and demonstration of tunable optical limiting properties. Chemistry of Materials 21, 2950-2956 (2009).

26. Kang, Y. et al. An amorphous carbon nitride photocatalyst with greatly extended visible-light-responsive range for photocatalytic hydrogen generation. Advanced materials 27, 4572-4577 (2015).

27. Wada, S., Tokunaga, A. T., Kaito, C. \& Kimura, S. Fitting the unusual UV extinction curve of V348 Sgr. Astronomy and Astrophysics 339, L61-L64 (1998).

28. Tan, Z. et al. Interstellar analogs from defective carbon nanostructures account for interstellar extinction. The Astronomical Journal 140, 1456 (2010).

29. Tauc, J., Grigorovici, R. \& Vancu, A. Optical properties and electronic structure of amorphous germanium. physica status solidi (b) 15, 627-637 (1966).

30. Dhineshbabu, N. R., Rajendran, V., Nithyavathy, N. \& Vetumperumal, R. Study of structural and optical properties of cupric oxide nanoparticles. Applied Nanoscience 6, 933-939, doi:10.1007/s13204-015-0499-2 (2016).

31. Roy, S. \& Rhim, J.-W. Melanin-Mediated Synthesis of Copper Oxide Nanoparticles and Preparation of Functional Agar/CuO NP Nanocomposite Films. J Nanomater 2019, 2840517, doi:10.1155/2019/2840517 (2019).

32. Toda, M. et al. Green chemistry: biodiesel made with sugar catalyst. Nature 438, 178 (2005).

33. Tsubouchi, N., Xu, C. \& Ohtsuka, Y. Carbon crystallization during high-temperature pyrolysis of coals and the enhancement by calcium. Energy \& fuels 17, 1119-1125 (2003).

34. Mishra, A. K. \& Ramaprabhu, S. Carbon dioxide adsorption in graphene sheets. AIP Advances 1, 032152 (2011).

35. Gandhi, S. et al. Ultrasound assisted one pot synthesis of nano-sized CuO and its nanocomposite with poly (vinyl alcohol). Journal of materials science 45, 1688-1694 (2010).

36. Pandey, R. K., Singh, A. K. \& Prakash, R. Enhancement in performance of polycarbazole-graphene nanocomposite Schottky diode. AIP Advances 3, 122120 (2013).

37. Kim, J.-H., Cho, H., Ryu, S.-E. \& Choi, M.-U. Effects of metal ions on the activity of protein tyrosine phosphatase VHR: highly potent and reversible oxidative inactivation by Cu2+ ion. Archives of Biochemistry and Biophysics 382, 72-80 (2000). 
38. Beveridge, T. \& Murray, R. Sites of metal deposition in the cell wall of Bacillus subtilis. Journal of bacteriology 141, 876-887 (1980).

39. Doyle, R. J., Matthews, T. H. \& Streips, U. N. Chemical basis for selectivity of metal ions by the Bacillus subtilis cell wall. Journal of bacteriology 143, 471-480 (1980).

40. Azam, A. et al. Antimicrobial activity of metal oxide nanoparticles against Gram-positive and Gramnegative bacteria: a comparative study. International journal of nanomedicine 7, 6003 (2012).

41. Zhao, G. et al. Magnetic Nanoparticles@Metal-Organic Framework Composites as Sustainable Environment Adsorbents. J Nanomater 2019, 1454358, doi:10.1155/2019/1454358 (2019).

42. Mali, S. C., Dhaka, A., Githala, C. K. \& Trivedi, R. Green synthesis of copper nanoparticles using Celastrus paniculatus Willd. leaf extract and their photocatalytic and antifungal properties. Biotechnol Rep (Amst) 27, e00518-e00518, doi:10.1016/j.btre.2020.e00518 (2020).

\section{Figures}

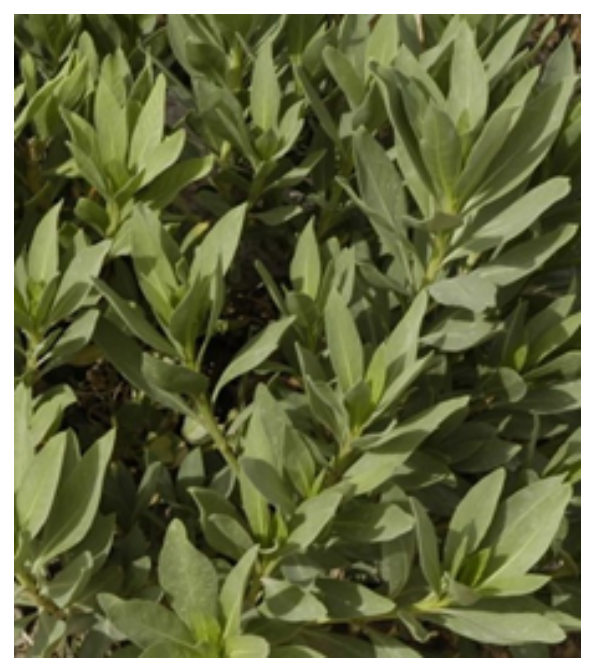

\section{Figure 1}

Photo of Rhazya stricta plant in natural habitat 

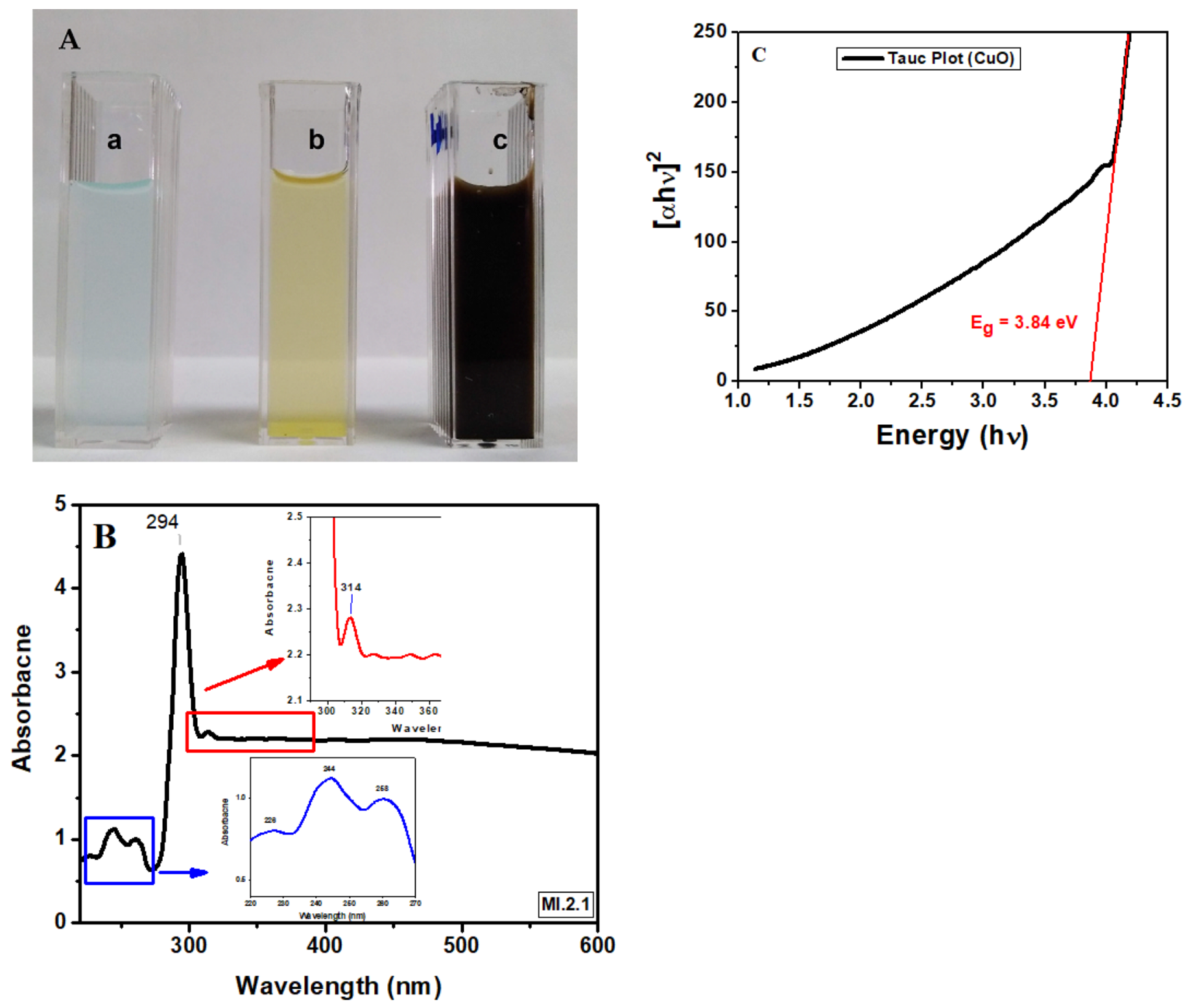

Figure 2

(A) Photograph of sample changing color (a) aqueous CuSO4 solution, (b) aqueous extract of Rhazya stricta, (c) aqueous solution of CuO NS. (B) UV visible absorption spectrum of CuO nanosheets. (C) Tauc's plot showing the energy bandgap of CuO NS 


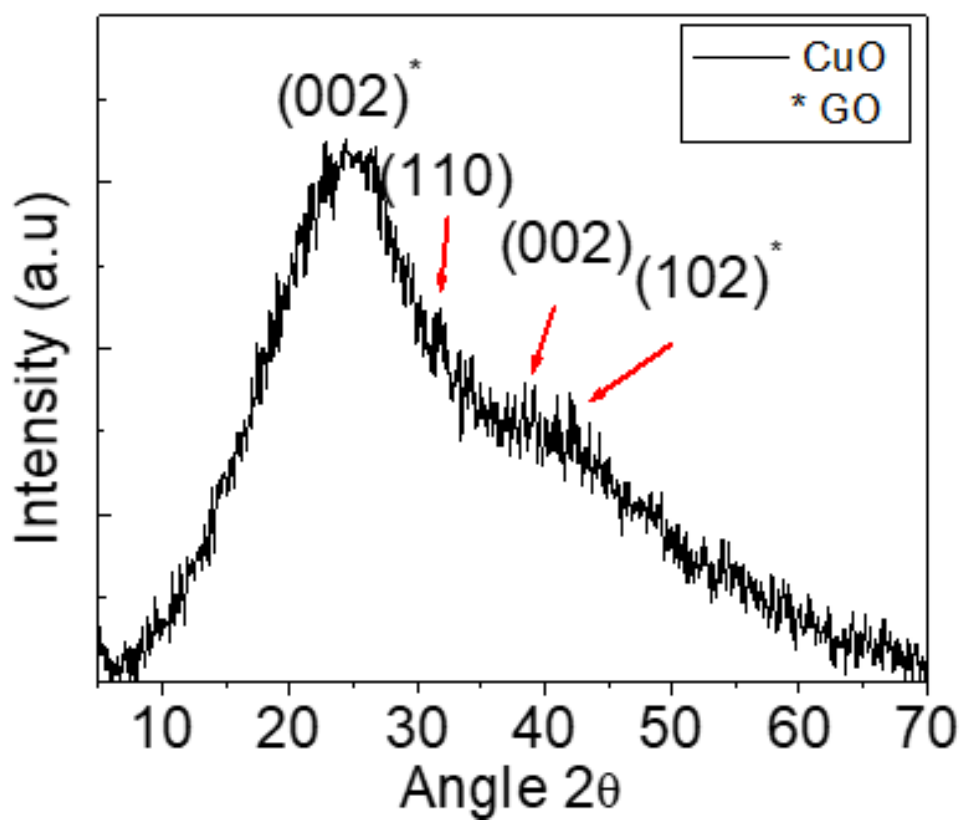

Figure 3

XRD spectrum of CuO NS synthesized via green synthesis using Rhazya stricta aqueous extract showing major diffraction peaks

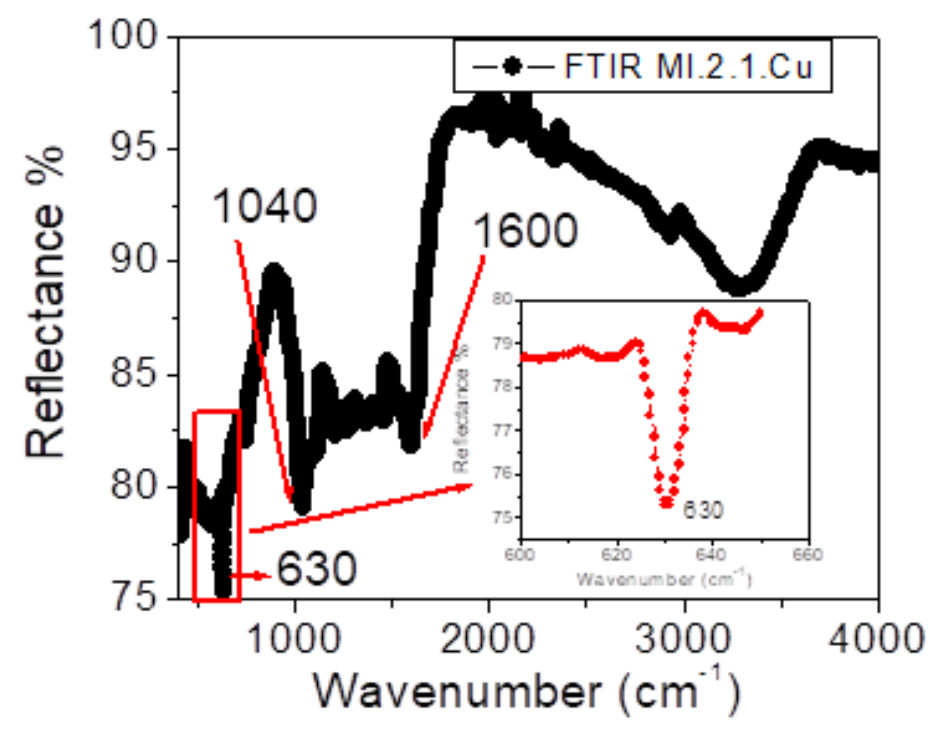

Figure 4

FTIR spectrum showing various absorption bands. The inset magnified part of the spectrum showing clearly the sharp peak at $630 \mathrm{~cm}-1$ correspondings to the formation of pure $\mathrm{CuO}$ nanosheets. 

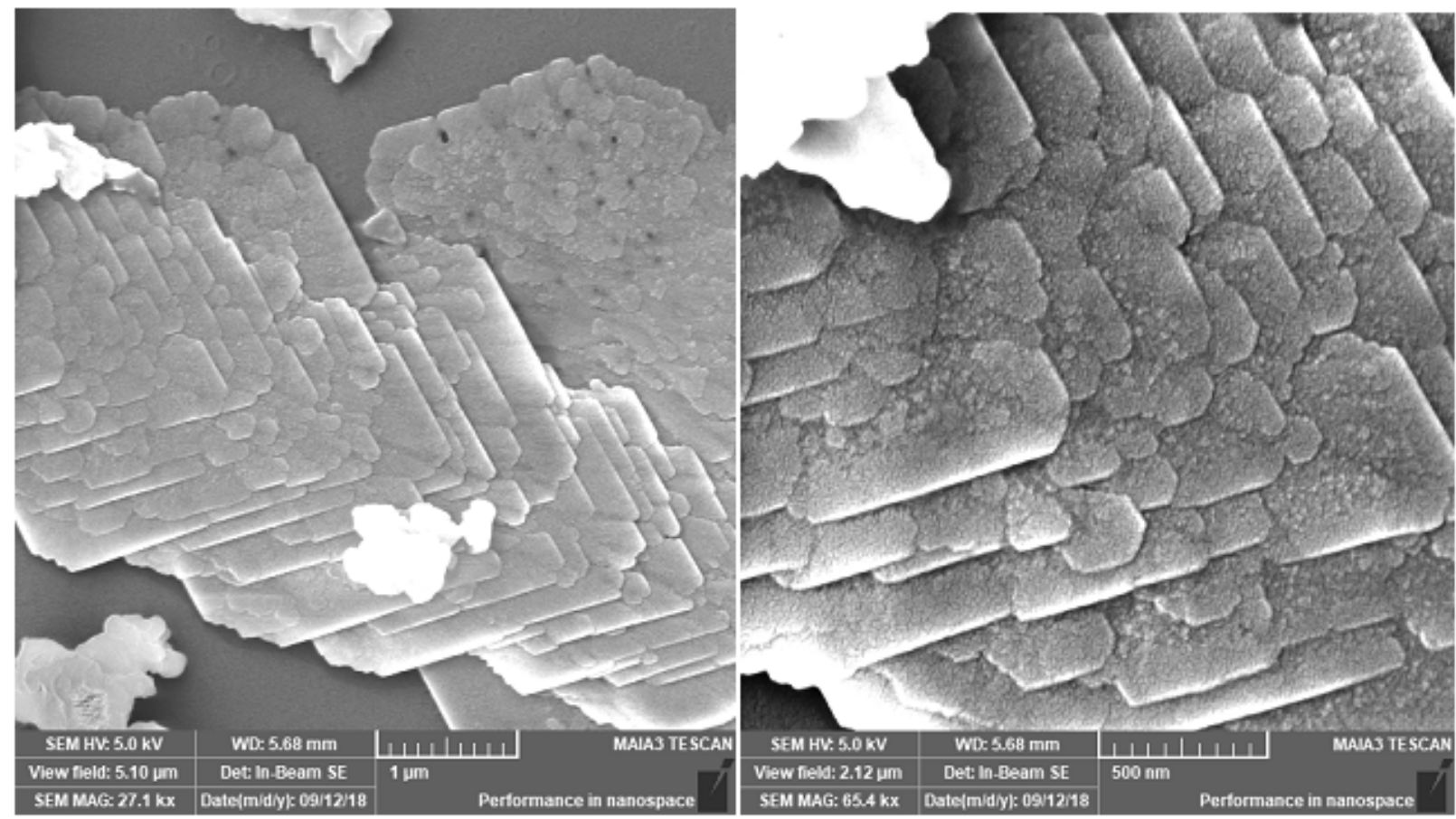

\section{Figure 5}

SEM image as-formed Copper Oxide nanosheets

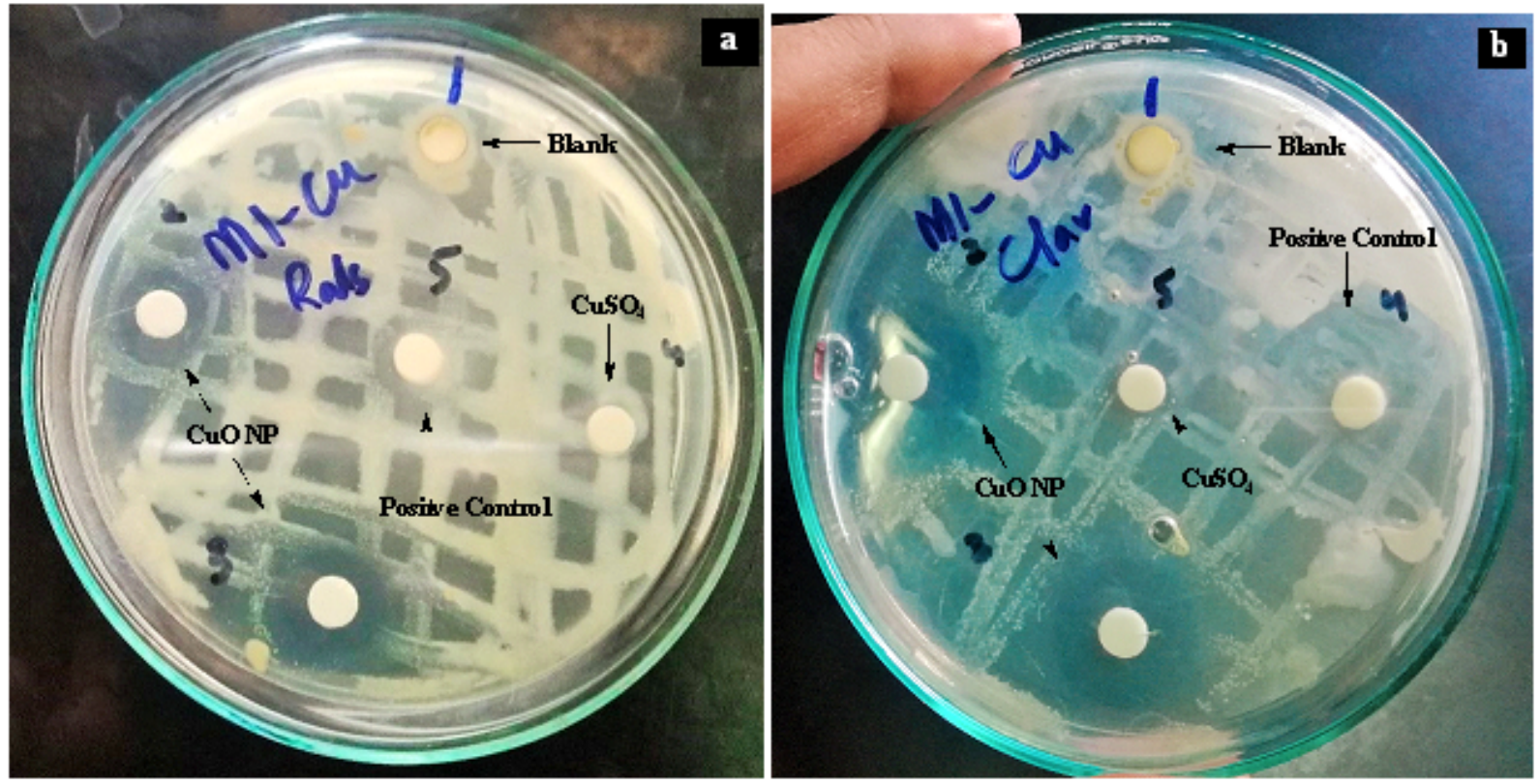

Figure 6

Zone of inhibition of (a) Ralstonia solanacearum and (b) Clavibacter michiganensis. 

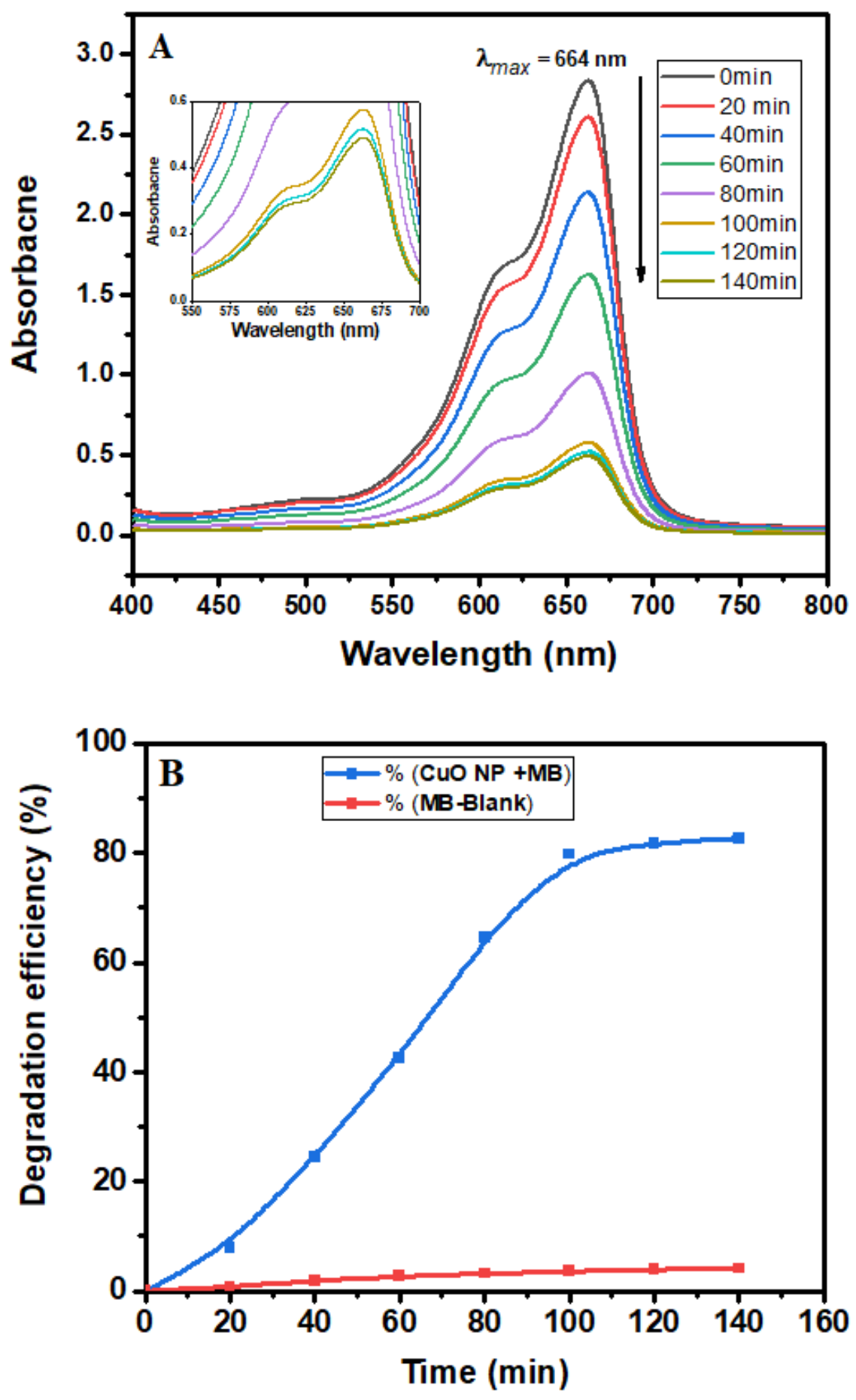

Figure 7

(a) Photocatalytic degradation of MB using CuO NS, (b) degradation efficiency (\%) of MB 


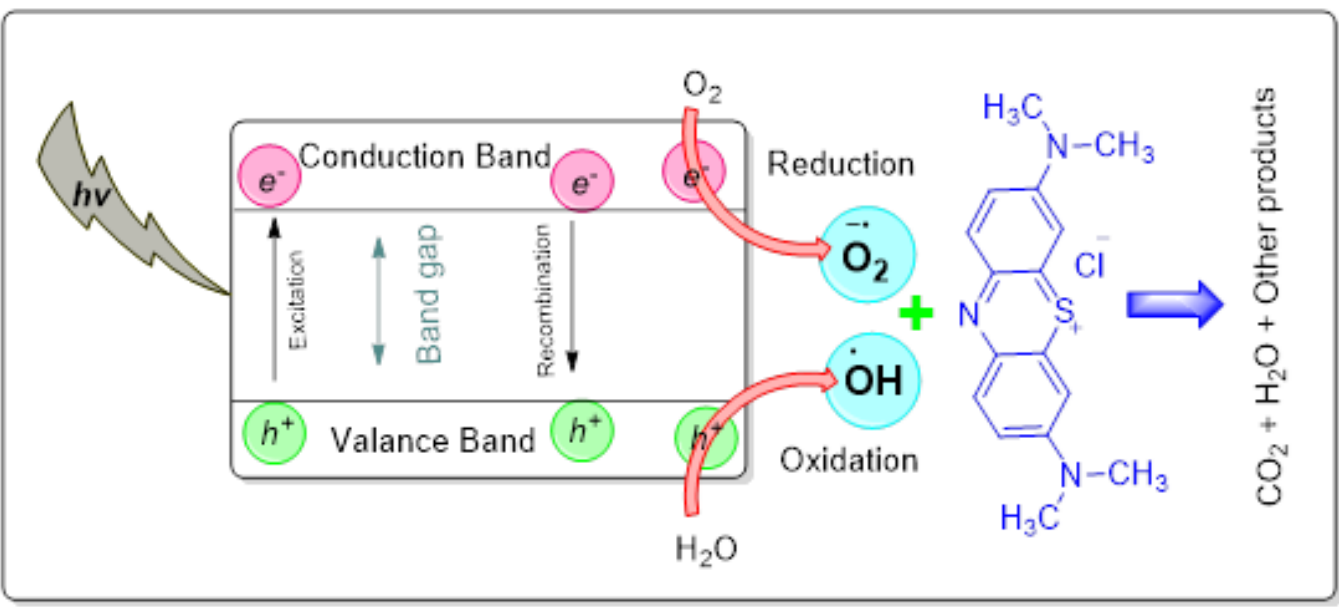

\section{Figure 8}

Mechanism of photocatalytic degradation of methylene blue using CuO NS 